\title{
Acupuncture at Tàichōng (太冲 LR 3) for dysmenorrhea
}

\author{
ABDURACHMAN $^{\mathrm{a}, \mathrm{b}, *}$, Krisnawan Andy PRADANA ${ }^{\mathrm{b}, \mathrm{c}}$, HAMZAH $^{\mathrm{d}}$, Hendy HENDARTO ${ }^{\mathrm{e}}$ \\ a Traditional Medicine Study Program (BATTRA), Faculty of Vocational Studies, Airlangga University, Surabaya 60231, Indonesia \\ ${ }^{\mathrm{b}}$ Department of Anatomy and Histology, Airlangga University, Surabaya 60231, Indonesia \\ ${ }^{\mathrm{c}}$ Department of Molecular Biology, University of Surabaya, Surabaya 60231, Indonesia \\ ${ }^{\mathrm{d}}$ Department Anesthesiology and Reanimation, Soetomo Hospital, Airlangga University, Surabaya 60231, Indonesia \\ e Department of Obstetrics and Gynecology, Soetomo Hospital, Airlangga University, Surabaya 60231, Indonesia
}

\section{A R T I C L E I N F O}

\section{Article history:}

Available online 11 September 2018

\section{Keywords:}

Acupuncture

Tàichōng (太冲 LR 3)

Dysmenorrhea

\begin{abstract}
A B S T R A C T
The patient with dysmenorrhea was treated by needling at Tàichōng (太冲 LR 3), 4 times of treatment was given and the nausea, migraine and pain scale of the patient were alleviated and finally disappeared. Until the next two menstrual period, patient did not have similar complaints. The author recommended for other acupuncturists to utilize LR 3 as complementary therapy for relieving pain at primary dysmenorrhea.
\end{abstract}

(C) 2018 Published by Elsevier B.V. on behalf of World Journal of Acupuncture Moxibustion House.
Dysmenorrhea is a period pain that commonly occur in women, following with painful cramps during menstruation, especially for young women in reproductive age [1,2], classified as primary and secondary dysmenorrhea [3]. More than half of all girls and women suffer from dysmenorrhea [4]. Primary dysmenorrhea characterized different with secondary dysmenorrhea, but they are related [3-7]. Chronic diseases, like dysmenorrhea, can decrease or even loss productivity [8]. Nonsteroidal anti-inflammatory drugs (NSAID) often used as initial therapy, even though it related with many kind of side effect [2,9]. Instead of using NSAID or pharmacological drugs, there are therapy for dysmenorrhea, called acupuncture and acupressure $[2,10]$. There had been many manners used to overcome pain caused by dysmenorrhea $[11,12]$, but still not perfect.

Acupuncture, is the insertion of fine needles to acupoints, usually applied by finger or thumbs [13-15]. Acupuncture can be compared to few medication, such as NSAIDs, combined oral contraceptives (COC), Tamoxifen citrat, and acupuncture give significant effect rather than other medications, also give increasing quality of life [16]. Somehow, late study and general therapy by using acupuncture treatment at dysmenorrhea involve multipoint needles insertion [17-31]. This paper aiming to report clinical effectiveness of acupuncture at Tàichōng (太冲 LR 3) for relieving pain at dysmenorrhea. Also from this report will be known the effect of single point needle insertion on LR3, which point far from the trunk, it is ease to be performed, even if by a doctor who do not

\footnotetext{
* Corresponding author at: Traditional Medicine Study Program (BATTRA), Faculty of Vocational Studies, Airlangga University, Surabaya 60231, Indonesia

E-mail address: abdurachman@fk.unair.ac.id (ABDURACHMAN).
}

understand acupuncture, because a doctor will know anatomy so well.

This case report began from the date of January 10, 2018. The patient complained dysmenorrhea. This complaint has been a long time, since before marital. Due to menstrual pain, patient could have had even up to 1-2 days lie down, unable to get up. Patient usually took analgesic for relieving pain, for example spasminal. According to patient's information, on several times of gynecological check-up, no cysts, no uterine myoma or other disorders were found. The patient ever had an ectopic pregnancy, in the right side fallopian tube at the end of year 2010. Ectopic pregnancy broke out on 1 February 2011 at 8 weeks' gestational age. The right side fallopian tube was removed. Until this report patient never got pregnant anymore.

While interviewing and anamnesis was taken, the patient received therapy. Conducted therapy by Dr. Abdurachman. The acupoint that has to be treated was sterilized using cotton alcohol $75 \%$. The acupuncture's needle $(0.25 \times 25 \mathrm{~mm}$ in size, HuanQiu brand) was inserted perpendicular at LR 3. LR 3 corresponds to liver meridian according to meridian theory in acupuncture. The needle was rotated to the left and right. The deep of needle reaches $7 \mathrm{~mm}$. Related to anatomy, point LR 3 located on the dorsum of the foot in a depression, distal to the junctions of the first and second metatarsal bones. Needle was rotated for $8 \mathrm{~s}$ on LR 3 point. The patient was asked about the complaints of her pain.

The treatment is divided into 4 sessions of therapy: 10, 11, 15 and 18 of January 2018. Until the menstrual period of March 2018, patient did not have similar complaints. The information comes through doctor-patient communication via WhatsApp on month before this paper submitted. Acupuncture therapy using LR 
Table 1

Treatment progress of needling at LR 3 for dysmenoria.

\begin{tabular}{ll}
\hline $\begin{array}{l}\text { Day of } \\
\text { therapy }\end{array}$ & Progress \\
\hline 1st & $\begin{array}{l}\text { No nausea - headache appear, from pain scale } 7 \text { (scaled 1-10) } \\
\text { suddenly disappearing - only the trace pain remains } \\
\text { Mild cramp, spot showed, no migraine anymore after waking up in } \\
\text { the morning }\end{array}$ \\
Cramp reduced to scale $1-2$ from scale 10. Migraine just appearing \\
one time, suspected due to excessive activity and delayed meals. \\
Menstruation appears as the fresh blood, previously appeared as \\
darkish matter. From last treatment, not using pain-killer \\
anymore \\
Migraine and menstrual pain gradually disappear
\end{tabular}

3 point on dysmenorrhea, resulting significant qualitative progress, as shown in Table 1.

\section{Discussion}

Pain has a valuable role in the medical action, therefore [32]. Pain itself based on the duration, classified as chronic and acute [32]. Chronic pain is a disabling condition, it affects every aspect of a patient's life, contributing to a loss of both physical and emotional function, affecting a patient's activity (ability to work at home and job and engage in social and recreational pursuits) [33]. Pain divided into somatic and visceral. True visceral pain arises as a diffuse and poorly defined sensation usually perceived in the midline of the body, at the lower sternum or upper abdomen [34]. Psychophysics of visceral pain differs from somatic pain, and it needs to be examined carefully while the neurological mechanism of somatic pain cannot extrapolate to visceral pain without qualification [35]. As said before, dysmenorrhea divided into primary and secondary. Primary dysmenorrhea contains symptoms that occurred within 8-72 h of menstruation like crampy, colicky spasm of pain in the suprapubic area, and also peaking within the first few days as menstrual flow increases [16]. Headache, nausea and vomiting are the sign of prostaglandins and others metabolites entering general circulation [36].

Nowadays, acupuncture is often used as secondary therapy for dysmenorrhea. It increases uterine blood flow through ovarian sympathetic nerve reflex, and changes prostaglandin levels [16]. There is proposed hypothesis by the year of 2010 that descended pain in primary dysmenorrhea occurs by stimulation of common acupoints, including Guānyuán, (关元 CV 4), Sānyīnjiāo (三阴交 Sp6), and Dìjī (地机 Sp8) that transmit signals via afferent pathways to the midbrain [37]. From those late researches, we will understand the golden goal by using acupoint at LR 3 is really comfortable for patients. On the another hand, by using LR 3, our case report showed that healing on dysmenorrhea is relatively fast, perfect and no recurrence at least during therapy period. The authors recommended for other acupuncturists to utilize LR3 as complementary therapy for relieving pain at primary dysmenorrhea. The authors had used LR 3 point to get the same effect for many times however not yet publish. For further more credible report, all of the patient's information data should be recorded since marital and long time before. The same complaint related dysmenorrhea should be evaluated by the time after therapy. In this case, all those data cannot be provided because the patient came to Surabaya proper to visit her parents. Her daily occupation was in Jakarta.

\section{Disclosure statement}

The authors declare that they have no conflicts of interest and no financial interests related to the material of this manuscript.

\section{Acknowledgments}

We would like to express our gratitude and appreciation to the patient who contribute to this paper.

\section{Supplementary materials}

Supplementary material associated with this article can be found, in the online version, at doi:10.1016/j.wjam.2018.09.002.

\section{References}

[1] French L. Dysmenorrhea in adolescents: diagnosis and treatment. Paediatric Drugs 2008;10(1):1-7

[2] French L. Dysmenorrhea. Am Family Phys 2005;71(2):285-91.

[3] Proctor M, Farquhar C. Diagnosis and management of dysmenorrhoea. BMJ Br Med J 2006;332(7550):1134-8

[4] H, Jones M, Mishra G. The prevalence and risk factors of dysmenorrhea. Epidemiol Rev 2014;36(1):104.

[5] Dawood MY. Primary dysmenorrhea: advances in pathogenesis and management. Obstetr Gynecol 2006;108(2):428-41.

[6] Zahradnik HP, Hanjalic-Beck A, Groth K. Nonsteroidal anti-inflammatory drugs and hormonal contraceptives for pain relief from dysmenorrhea: a review. Contraception 2010;81(3):185-96.

[7] Latthe P, Latthe M, Say L, et al. WHO systematic review of prevalence of chronic pelvic pain: a neglected reproductive health morbidity. BMC Public Health 2006;6(1):1-7.

[8] Burton WN, Morrison A, Wertheimer AI. Pharmaceuticals and worker productivity loss: a critical review of the literature. J Occup Environ Med 2003;45(6):610-21.

[9] Tramèr MR, Moore RA, Reynolds DJ, et al. Quantitative estimation of rare adverse events which follow a biological progression: a new model applied to chronic NSAID use. Pain 2000;85(1):169-82.

[10] Tzafettas J. Painful menstruation. Pediatr Endocrinol Rev Per 2006;3(Suppl 1(Suppl 1)):160-3.

[11] Kuphal GJ. Dysmenorrhea in integrative medicine. Available from: http:// linkinghub.elsevier.com/retrieve/pii/B9780323358682000578.

[12] Ryan SA. The treatment of dysmenorrhea. Pediatr Clin North Am Apr 2017;64(2):331-42.

[13] Beal MW. Acupuncture and acupressure. Applications to women's reproductive health care. J Nurse Midwifery Jun 1999;44(3):217-30.

[14] White A, Ernst E. A brief history of acupuncture. Rheumatology (Oxford) 2004;43(5):662-3.

[15] MacPherson H. Towards better reporting of interventions in clinical trials of acupuncture. J Chinese Integr Med 2010;15:801-3.

[16] Smith C A, Armour M, Zhu X, et al. Acupuncture for dysmenorrhea. Cochrane Database Syst Rev 2011;4(1) CD007854.

[17] Chen S Z, Cong Q, Zhang B F. Preliminary comparison on the time-effect rule of pain-relieving in the treatment of moderate dysmenorrhea between acupuncture on single-point and acupuncture on multi-point. Zhongguo Zhen Jiu 2011;31(4):305-8.

[18] Li Y-M, Bu Y-Q, Hou W-J, Chen SZ, Gao S-Z. Observation on immediate analgesic effect of acupuncture at Shiqizhui (EX-B 8) only or multi- points in patients with dysmenorrhea: a randomized controlled trial. Zhongguo Zhen Jiu 2011;31(3):199-202.

[19] Ma Y-X, Ye X-N, Liu C-Z, Cai P-Y, Li Z-F, Du D-Q, et al. A clinical trial of acupuncture about time-varying treatment and points selection in primary dysmenorrhea. J Ethnopharmacol 2013;148(2):498-504

[20] Bu Y-Q, Du G-Z, Chen S-Z. Clinical study on the treatment of primary dysmenorrhea with preconditioning acupuncture. Chin J Integr Med 2011;17(3):224-7.

[21] Charandabi SMA, Nashtaei MS, Kamali S, Majlesi R. The effect of acupressure at the Sanyinjiao point (SP6) on primary dysmenorrhea in students' resident in dormitories of Tabriz. Iran J Nurs Midwifery Res 2011;16(4):309-17.

[22] Chen H-M, Chen C-H. Effects of acupressure at the Sanyinjiao point on primary dysmenorrhoea. J Adv Nurs 2004:48(4):380-7.

[23] Chen $\mathrm{H}$ M, Chen C H. Effects of acupressure on menstrual distress in adolescent girls: a comparison between Hegu-Sanyinjiao matched points and Hegu, Zusanli single point. Journal of Clinical Nursing 2010;19(7-8):998-1007.

[24] Cho S-H, Hwang E-W. Acupuncture for primary dysmenorrhoea: a systematic review: acupuncture for primary dysmenorrhoea. BJOG Int J Obstetr Gynaecol 2010;117(5):509-21.

[25] Lee SH, Ahn SC, Lee YJ, Choi TK, Yook KH, Suh SY. Effectiveness of a meditation-based stress management program as a complementary to pharmacotherapy in patients with anxiety disorder. J Psychosom Res 2007;62(2):189-95.

[26] Li PP. Toward an integrative framework of indigenous research: the geocentric implications of Yin-Yang Balance. Asia Pacif J Manag 2012;29(4):849-72.

[27] Ma Y-X, Ma L-X, Liu X-L, Ma Y-X, Lv K, Wang D, et al. A comparative study on the immediate effects of electroacupuncture at Sanyinjiao (SP6), Xuanzhong (GB39) and a non- meridian point, on menstrual pain and uterine arterial blood flow, in primary dysmenorrhea patients. Pain Med 2010;11(10):1564-75.

[28] Mirbagher-Ajorpaz N, Adib- Hajbaghery M, Mosaebi F. The effects of acupressure on primary dysmenorrhea: a randomized controlled trial. Compl Ther Clin Pract 2011;17(1):33-6. 
[29] Song J-S, Liu Y-Q, Liu C-Z, Xie J-P, Ma L-X, Wang L-P, et al. Cumulative analgesic effects of EA stimulation of sanyinjiao (SP 6) in primary dysmenorrhea patients: a multicenter randomized controlled clinical trial. Zhen Ci Yan Jiu 2013;38(5):393-8.

[30] Sun S-H, Choi W-J, Cho Y-Y. The effects of Sa-am acupuncture Simpojeongkyeok treatment on the blood pressure, pulse rate, and body temperature. J Pharmacop 2015;18(2):33-41.

[31] Wang H-B, Zhao S, Sun N, Li X-Q, Ma S-X, Li Q, et al. Efficacy observation on wrist-ankle needle for primary dysmenorrhea in undergraduates. Zhongguo Zhen Jiu 2013;33(11):996-9.

[32] Raffaeli W, Arnaudo E. Pain as a disease: an overview. J Pain Res 2017;Volume $10: 2003-8$
[33] Turk DC, Wilson HD, Cahana A. Treatment of chronic non-cancer pain. Lancet 2011;377(9784):2226-35.

[34] Sikandar S, Dickenson AH. Visceral pain: the ins and outs, the ups and downs. Curr Opin Suppor Palliat Care 2012;6(1):17-26.

[35] Cervero F, Cervero F. Pathophysiology of visceral pain. Der Schmerz 2014;28(3):252-8.

[36] Howard FM. Pelvic pain: Diagnosis and management, Philadelphia: Lippincott Williams \&Wilkins; 2000. 529.

[37] Smith CA, Crowther CA, Petrucco O, et al. Acupuncture to treat primary dysmenorrhea in women: a randomized controlled trial. Evidence-Based Complementray and Alternative Medicine 2011;2011(7):612464 (2010-09-15), 2010. 